\title{
The Influence of User Generated Content on Purchase Intention of Automobiles in Sri Lanka
}

\author{
Thilina Karunanayake $^{1} \&$ Chapa Madubashini ${ }^{1}$ \\ ${ }^{1}$ Department of Marketing Management, Faculty of Commerce and Management Studies, University of Kelaniya, \\ Sri Lanka \\ Correspondent: Thilina Karunanayake. E-mail: thilinasq@live.com
}

Received: April 29, 2019

Accepted: May 7, 2019

Online Published: May 31, 2019

doi:10.5539/ass.v15n6p44

URL: https://doi.org/10.5539/ass.v15n6p44

\begin{abstract}
The purpose of this study to identify the influence of user generated content on purchase intention of automobiles in Sri Lanka. The said study is based on the theory of Uses and Gratification and supportive findings. This study has been addressed the survey type research method and structured questionnaire was used to collect data and utilize sample frame of automobile followers on Facebook. Measuring the influence of user generated content on purchase intention through developed hypotheses. Researchers have used analysis technique of descriptive analysis, regression, and frequency test where statistical package for social science (SPSS) was used as the main analytical software.

The results of the study discuss the main eight element affect the purchase intention of automobiles, but the two elements not strongly affect the purchase intention which were namely, homophily and trust. These two elements have weak relationship with the purchase intention. Mainly consumer resonance mediating the user generated characteristics to purchase intention of automobiles. Hence this study has been significantly contributing to the existing knowledge explaining the need, motivation (users and gratification) - consumer resonance-intention linkage in customer behaviour.
\end{abstract}

Keywords: purchase intention, uses and gratifications, consumer resonance, user generated content, automobiles in Sri Lanka, social relation, self-presentation

\section{Introduction}

The development of web 2.0 and new trends in the social media environment that change on a consumer's behaviour and media research is moving, its focus to a greater extent on the media users. This situation to be investigated by marketing researchers to understand, how consumer make decisions regarding a purchase, and making purchase starts a chain reaction of value creating actions. Consumers are seeking activities which creating value that takes place as people go about and attempting to address real needs (Kim \& Rao, 2008; Kim, 2012; Hazari \& Sethna, 2016). Though consumer motivates by needs, they find ways in which to meet this need and the process involves the multiple psychological events which include thinking, feeling and behaving the entire process generates in value (Hazari, 2016). It could be found that the processes mentioned been used to get an idea about the customers and persuade them to get into social circles while make an impact on their perceptions towards goods and services (Hazari, 2016; Shang, Wu, \& Sie, 2017). By social media environment, consumers are influenced when they retrieved information to make their purchase intention. It has also identified that people do read content on social media before they making a purchase intention (Hazari, 2016). Once the people into put like, replying and sharing the content in the social media gives a sign that they have read the content and also agree on the content given by the product or a service.

This paper considers that, the consumer's intention is very much important to count on the usage behaviour and people who search and see content which higher volume of resonance behavior lead to a higher purchase intention of product and services (Shang, 2017; Shao, 2009). In this new digitized era marketing communication craft new opportunities to address customers. In this context Social media plays a vital role in creating a buzz with digital content targeted at customers. With this immerging social media networks, users tend to share their ideas relating to product and services. This content created by users in these social media platforms pave the way to identified the concept of "User Generated Content" (UGC). The online information market continues to shift to user centric model and the use of consumer engagement and participation in virtual communities has been 
research interest to marketers who are looking at to investigate phenomenon related to UGC in the digital marketing environment. Previous research has explored UGC related to topics such as consumer engagement, electronic word of mouth, online brand reputation management, customer relationship management and social network analysis (Hazari et al., 2016; Shao, 2009).

The wide presentation of the internet has led to interest in the "uses and gratification theory". In which, internet users actively choose which site to visit and community to join, what content read and post so on. These actions evolve the decisions and open new field of study of person uses and gratification (Azi, 2015; Shang, 2017; Hazari, 2016). Therefore, uses and gratification may vary based on the characteristic of the audience, for an example motivation for internet usage depend on users' age and socioeconomic status young crowed from a high socioeconomic state trend to use the internet for getting information to need for specific tasks as well as develop the relationship and their knowledge about the product categories what they are interested (Katz \& Gurevitch, 1973 as cited in Shang et al., 2017).

In contrast to Sri Lankan context, type of the product is the dominant factor that decides the purchase choice of the consumers and mainly navigation speed and information richness are major concerns of consumers and the search for durable goods through the social media sites (Herath \& Wijesundara, 2008; Hazari \& Sethna, 2016). According to the digital global survey of 10,000 consumers in 2014, the average engagement rate of the automobile industry is relatively higher than the average engagement rate of the Facebook page. Market composition of automobiles in Sri Lanka, at the decreasing rate when considering the other countries.

In this study researcher carried out in-depth analysis of literature on considered research and stated in following section to mediate the consumer resonance in mediate on the relationship between purchase intention and user generated content, provided by creating adequate knowledge in explaining the concepts of user generated content, purchase intention decided from U\&G theory.

\section{Literature Review}

\subsection{User Generated Content}

The word user generated content has a broad scope as indicated from recent literature where researchers have conducted studies providing different circumstances of UGC and shows the different faces of UGC. When web 2.0 represents the foundation of technology, UGC can be seen as the sum of all ways in which people make use of social media, it's usually applied to describe the various forms of media content that are publicly available and create by end users. It needs to satisfy basic requirements: first, it should be published on the publicly accessible website or social networking sites, second, should be shown a creative effort and finally, needs to have been created outside of the professional routines and practices (Kaplan \& Haenlein, 2010; Mangold \& Faulds, 2009). It can be taken in various forms such as individually or collaboratively as product, modified, shared and consumed and the most relevant is consumer product reviews and recommendations ( $\mathrm{Mu}$ niz \& Schau, 2007)

The relevant research streams on UGC can be found in previous literature (Chevalier \& Mayzlin, 2006; Lee \& Han, 2008; as cited in Hazari et al., 2016). The first study investigate the consumer generated advertisements and brand for an example, what motives customers to create certain content and how they manage the co- creation (Berthon, 2008; Burmann, 2010, the second analysis how credible consumers find UGC and their goals engaging that content created by them (Chari, Christodoulides, Presi, Wenhold, \& Casaletto, 2016), finally that focuses on the relationship UGC and significant msnsgiaral outcomes as sales (You, Vadakkepatt, \& Joshi, 2015) .The types of comments made by reviewers and they have ability to influence sales, for an example, Ghose \& Ipeirotis, (2011) investigated that correlation between product sales and type of reviews that include the more information and attraction of content, they found that the reviews mixed with the subjective and objective judgments that have less impact on the product sales than reviews.

\subsection{Purchase Intention}

The consumer's purchase decision process, employed through which the buyer passes in purchasing a product or services and those steps include: problem recognition where the consumer recognizes a problem. For example, one person 's car was having technical issues for the last six months; search information where the consumer thinks about options he/she may have to cover for this situation. And he/she consider for external sources of information such as friends, newspapers, magazine, TV, and the internet and also social media. Gogoi, (2013), defined that the identification and evaluation where a person might have some ideas about what alternatives he/she has and how to adapt them. After person differentiate the options; Choice and purchase where the consumer purchases the most attractive option he/she has recognized; According to the (Selejan, 2014) explained that the post purchase evaluation happens where the consumer experiences his/her choice and determines if 
he/she is happy with it; Feedback learning for future consumption behavior where the consumer remembers how he/she feels about purchase and makes note of it for future reference. Karunanayake \& Wanninayake, (2015), demonstrated that, in some situations not each consumer passed through all these stages when making a choice to purchase and in fact, some of the steps can be missed depending on the type of purchases.

According to Karunanayake (2015), consumers evaluate several factors through their decision making process and they use degree of importance, of vehicle components or group of factors that reduce the items. These evaluations can be seen in terms of consideration set and finally applied to purchase parameters. Those are final decision making or braking content for decision. The consumers can evaluate the performance by test driving the car and over word of mouth. Product ratings also relate to the performance and producer's perceived quality and attributes. When considering the consumer behaviour in towards automobiles, it can be explained as, the customers getting into to buying an automobile when they experience a strong desire or need for an automobile (Dholakia, 2001; Mark \& Natasha, 2003). For a consumer to get into the final decision, some of the consumers will consider and evaluate different factors as to their preferences and as a group, they are likely to take into consideration some basic elements like brand (Dk \& Gunawardane, 2019). Griskevicius, (2010) explained that these elements can be: cost, performance, the 'lifestyleimage' associated with some models, social influence and the automobile's environmental compliances like fuel economy emissions.

\subsection{Uses and Gratifications Theory}

In early 20th century, media began to penetrate the society and the researchers examined more on how media affects society. In this study presented the popular currents and ways of society interact with the media. Therefore, researchers found out that the media consumers more passive and influenced by mass media. After that media became the more diverse and users more interact with the media. The theory of uses and gratification which explained reasons for users select different media sources and what needs those selections wants to satisfy (West \& Turner, 2010).

Uses and gratifications (U\&G) theory was developed by Katz, (1973) as cited in Jahn \& Kunz, (2012) and it demonstrated the social need and psychological need are involved in creating expectations of the social media. It further mentioned that the different gratification needs that the people possess results in different means and modes of media usage. Further the Theory defines that people are goal directed with regard their needs and motives. Previous researchers found that, needs come from the social and psychological functions of mass media, it indicates that five categories of uses and gratification needs results in people use in mass media. According to the Chu and Kim, (2011); Jahn and Kunz et al., (2012), denote that the cognitive and affective needs under the utilitarian and hedonic value of the content that affect the consumer consumption. Hedonic values in content can be enjoyed when browsing information on social networks, fan pages, social integrative needs have been resulted to tie relationship, homophily, trust and interpersonal influence. The factors affect the personal integrative needs can be seen as the self-presentation gratification and it can be defined as people participate in activities on SNSs and the behaviour of the consumers can be recognize through these self-presentations. Tension release as a motivational escape is not discussed with the resonance behavior. As it putting more thoughts into the context, Shang et al., (2017) discussed three types of gratification namely, content gratifications, social relations gratifications, and self-presentation gratification.

Thus, during the last several decades, the theory of uses and gratifications has been adopted and developed in several perspectives, study the use of various media ranging from the more conventional mass media into the new media and concern the mobile technology (Stafford et al., 2004; Chigona et al., 2008; Roy, 2009; Shin, 2009; Liu et al., 2010). Although some researchers have demonstrated that U\&G's utility in studying the digital media, Ruggiero, (2009) as cited in Quan-Haase, (2012) posits there is a need to "seriously include" the U\&G approach in any attempt to speculate on the future direction of mass communication theory.

\subsection{Consumer Resonance}

The concept of resonance discussed with reference to the context of large number of responses that are created around a content which was created by an individual and in which others react quickly. As it pointed out by Solis (2010) and Riegne, (2007), there are three main features of social media to achieve social media goal, those are namely, relevance, resonance and significant. Business should focus on generating content which are related to its product and services which can lead to the resonance with consumers. From individual viewpoints, it has further mentioned that resonance is a cognitive engagement in which an audience participates in media (Shang, 2017).

Libai, (2010) has been demonstrated that, the resonance is a precondition of word of mouth (WOM) behaviour and refers to interaction between customers in an online environment. When customers aware and engaged, they 
have a willingness to communicate with others (Hoffman and Fodor, 2010). The difference between these consumer resonances and WOM.

Consumers who have emotional and useful benefits and encourage to participate in an online discussion and individual that share information with their friends enhance the resonance (Li \& Shiu, 2012) on SNSs. Tickel and Rosenthal, (1990) as cited in Shang, (2017) explained clearly when people say the clicked with each other or felt the good interaction. Moreover, consumers can be defined as that relevant consumers are likely to make with a firm's product or services.

\section{Conceptual Frame Work}

Uses and gratifications (U\&G) theory was developed by Katz (1973) as cited in Jahn \& Kunz (2012) and it demonstrated the social need and psychological need are involved in creating expectations of the social media. It further mentioned that the different gratification needs that the people possess results in different means and modes of media usage. Further the Theory defines that people are goal directed with regard their needs and motives. In the literature it identified five categories of uses and gratifications needs that define the usage of mass media of people (Katz, 1973; John, 2012). Cognitive, affective, social integration, personal integrative, and tension release. Cognitive needs exist where the people demands information for knowledge; affective needs exist where the people looking to have pleasurable or emotional experience; social integrative needs exist when the people want to interact with family, peers; personal integrative needs exist when people looking forward to get themselves with status and social recognition, finally, tension release needs exist when people looking to be relaxed and use media as a method of escapism from the real world (Shang 2017).

Jahn, 2012, pointed out that, hedonic values can be result in enjoyment as it searching for information on pages in social media networks. Next, the social integrative needs are results to (Chu \& Kim, 2011) social relationship gratifies that components of social relationships and networks include, tie strength, homophily, trust, and interpersonal influence. It has identified that these factors making an impact on all the activities on Social Network sites. Moreover, the personal integrative need could be related to the self-presentation gratification and that theorized by (Goffman, 1959 as cited in Shang, 2017) it states that people participate different activities on SNSs consumer behaviour could be understood through a self-presentation

\subsection{Relationship Between Content Gratification and Consumer Resonance on Facebook}

User's content gratification on social networks divided in to utilitarian and hedonic dimension through evaluating the consumer attitudes (Batar \& Ahtola, 1991; Mangold \& Faulds, 2009, as cited in Shang, 2017). Hence, following hypothesis is developed:

\section{H1: The content gratification of the content positively affects the consumer resonance on Facebook}

Utilitarian value as a consumer involving process such as collecting information out of necessity rather than reaction and information usefulness affect the degree to which information perceived by individuals to be helpful and informative. The other dimension with regards to content gratification is hedonic value (Batra and Ahtora, 1991 as cited in Shang, 2017) defined the hedonic value with related to emotional arousals and feelings in which cognitively consumption value significantly affect with the information on SNSs. In an online environment content treated as amazed, interesting, more likely to encourage engagement and creating discussion on the information. Thus, following hypothesis can be developed:

H1a: The utilitarian value of content positively affects the consumer resonance on Facebook.

H1b: The hedonic value of content positively affects the consumer resonance on Facebook.

\subsection{Relationship Between Social Relation Gratification and Consumer Resonance on Facebook}

With reference to the argument made by Chu and Kim, (2011), which stated that social relations making an impact on consumer engagement through five factors, following hypothesis is formulated:

H2: The social relation gratification characteristics of the content positively affects on consumer resonance on Facebook.

Tie strength, homophily, trust, normative influence and information influence positively effects on consumer resonance. Tie strength is a bond between members of the network that associate between connection individuals in an important function. While consumers browse on SNSs, choices of different kind of products may influence by both strong ties and weak ties (Chu, 2011). Perceived tie strength could motivate individuals to reply and exchange information on Facebook, the definition of homophily is the degree to which individuals who interact with others have certain similar characteristics and online environment, users are more likely to communicate and with those who are similar attributes, and trust factor as a willingness to rely on an exchange with partners 
whom one has confidence also the virtual community trust is an essential factor for individuals who take part in exchange message to another member and significant factor to make an impact on consumers' willingness. Thereby it can be concluded that, higher the trust, higher the resonance behaviour.

Interpersonal influence is the most important variable that affects the customer decision making, and it divided into two dimensions as, normative influence and information influence (Chu \& Kim, 2011).

As it pointed out by $\mathrm{Chu}$ and Kim, (2011) normative influence is discussed with related to expectation from others, which affect attitudes, norms and values. Accordingly, in situations where individuals who have higher degrees of normative influence most likely to communicate, reply share information on Facebook. Where the situations comprise informational influence, individuals looking forward to accept information from others. (Chu \& Kim, 2011). Therefore, following hypothesis can be developed:

H2a: The tie strength of a social relation positively affects the consumer resonance on Facebook.

H2b: The homophily within a social relation positively affects the consumer resonance on Facebook.

H2c: Trust within a social relation positively affects the consumer resonance on Facebook.

H2d: Normative influences of social relation positively affect the consumer resonance on Facebook.

H2e: Information influence of social relation positively affects the consumer on Facebook.

\subsection{Relationship Between Self-presentation Gratification and Consumer Resonance on Facebook}

Jahn and Kunz (2012) stated that self-presentation was identified as identity and social performance that will result in more self-assurance in an online environment. It has also made a point indicating that people looking forward to intensify their self-image and they engage through making comments, liking and sharing (Shang, 2017). Thus, the following hypothesis is developed:

\section{H3: Self-presentation positively affects consumer resonance on Facebook.}

\subsection{Relationship Between Consumer Resonance and Purchase Intention of Automobiles}

Chen, Hsu, and Lin, (2010) discussed that, Purchase intention most likely to take place as a result of a satisfaction and in the situation where individuals interacting with online environment individuals most likely to be influenced by information when they making a purchase decisions (Mangold \& Faulds, 2009). People do engage with the content before they make purchase decisions. As it discussed by Shang (2017), customers purchase intention is more important in deriving conclusions with related to usage behavior. Considering the fact that people expose with higher volumes of resonance behaviour could mediate intention to purchase the product (Shang, 2017), following hypothesis is formulated:

\section{H4: Consumer resonance on Facebook positively affects Purchase intention of automobiles}

$$
\text { User generated content }
$$



Figure 1. Conceptual Framework (Source: Author)

In this context, Researcher proposed a complete model for measuring influence of user generated content on purchase intention and depicted in Figure 1. 


\section{Methodology}

This paper developed the hypothesis and measure the independent, dependent variables based on a selected representative sample, the research approach going to be used "deductive approach" (Akbayrak, 2000). A deductive method refers to the use of logic of a theory to generate prepositions or hypotheses that can be tested. It also provides the need to explain the causal relationship between variables and required the collection of quantitative data as well. Bringing the motives for researcher to adopt a deductive approach: limited time; researcher focus wider scope of theories and conclusions derived from logical reasoning (Akbayrak et al., 2000).

\subsection{Measures}

This paper measures the influence of user generated content on purchase intention of automobiles in Sri Lanka which is having structured and formal research process. The current study will be a descriptive in nature while trying to derive a conclusion and dealing with numbers statistics and figures. Hence this study falling to quantitative study (Blumberg \& Schindler, 2008).

In the present study, is looking forward design the questionnaire by using two different measurement scales. Nominal and the interval scale. Nominal scale in the form of a simple category scale as well as multiple choice single response scale. On the other hand, interval scale has been used with the help of a 7poit Likert scale (Blumberg, 2008; Hazari, 2017).

Convenience sampling is a procedure in which a researcher's convenience from the basis for selecting the potential respondents. The researcher approaches the most accessible member of the population of interest". After the sample is determined, it should cover an element of the total population of the study. Hence, after sample determined it should cover an element of the total population of the study and it is important to limit and select a portion of the population which should represent the entire elements of the population in order to get correct conclusions. The population consists of a large number of respondents and it is problematic to use an information gathering. According to the researcher will be selected sample by using convenience sampling techniques. It should have minimized the errors in sample selection and it also required to denote the population by using those samples. The target population of this study is Sri Lanka automobile followers on Facebook. Since the difficulty in the collection of the data from entire population researcher goes to sample size 207 of Sri Lankans The researcher has selected the sample 207 respondents within the western province who are following auto pages on Facebook. Among the provinces with the highest level of computer literacy is reported from western province 38.6 percent as for the statistics depicted by the Department of Census and Statistics Report (2017).

All measurements were related on seven point Likert scale (anchored by "I strongly disagree" vs "I strongly agree". For the construct of framework which generated multi item scale on the basis of previous measures, the theoretical foundations. The measurement of utilitarian and hedonic values based on a scale from (Voss, 2003 as cited in Jahn, 2012). Social interaction value which adapted the social component of the social networking sites' gratifications system of (Barker, 2009 as cited in Jahn, 2012). Measurement of the self-concept value adapted from the social value component of the customer value system denote by (Sweeney and Soutar 2001 as cited in Jahn, 2012). Self-concept can be defined as utility derived from the fan page's ability to enhance social self-concept.

The underpinning theory for this study was $U \& G$ theory which is the most important theory in behavioral psychology consisting of having influential constructs and mediate which are making an impact on individuals' intention to purchase of a product (Hazari, 2017). With the given provision, items for the U\&G theory adapted from the U\&G theory and scale used by (Hazari, 2017; Shang, 2017) to relate to user generated content and purchase intention. Measuring the purchase intention, U\&G theory has deployed by 8 constructs namely: utilitarian value, hedonic value, tie strength, homophily, trust, normative influence, information influence and self-presentation. Those variables in U\&G theory directly affect the consumer resonance behaviour and into purchase intention.

The concept of consumer resonance that mediate variable in the study was measured through three items which is validated in the study of (Shang, 2017). The dependent variable of the developed model "Purchase intention" was measured through three items which is validated in the study of having a five point Likert scale.

Based on the discussion of above section and measurements adopted from previous researches, researcher has developed the questionnaire using 34 Likert scale items, to collect data, analyze and to derive conclusion on the influence of user generated content on purchase intention of automobiles in Sri Lanka. 


\subsection{Reliability and Validity Measures}

The collected data analysis and presentation was done through descriptive methods of SPSS, and by using some statistical methods. Correlation and multiple regression models used for further analysis and to identify the relationship between each variable considered. As independent variables, mediate variable and the dependent variable by testing the significance and acceptability of each hypothesis used in the study.

Statistical procedures have conducted to determine the objective of this study. Therefore, to achieve the purpose of the study and gratify the objectives of the study in a measurable way, used the following statistical techniques utilized to analyze the survey data of the sample.

Reliability is a measurement indicator that measures to what extent to measure are error free and as it consists the reliability it generates consistent measurement across time and across the various items in the instrument. Reliability test can be used as a measure that signals the consistency and stability of the instruments used in the survey when repeated measurements are made. A well-known approach to measure reliability is to use the Cronbach alpha. The value of Cronbach alpha with in general considered reliabilities less than 0.6 are poor, those in the 0.7 range is acceptable and those over 0.8 are good (Golafshani, 2003).

Table 1. Reliability Test

\begin{tabular}{|c|c|c|}
\hline \multirow{2}{*}{ Test } & Reliability & \multirow{2}{*}{ Number of Indicators } \\
\hline & Cronbach alpha & \\
\hline Standard & $<.7$ & \\
\hline (PI)_Purchase Intention & 0.873 & 3 \\
\hline (UV)_Utilitarian Value & 0.800 & 4 \\
\hline (HV)_Hedonic Value & 0.873 & 4 \\
\hline (TS)_Tie Strength & 0.816 & 3 \\
\hline (H)_Homophily & 0.893 & 3 \\
\hline (T)_Trust & 0.872 & 3 \\
\hline (NI)_Normative Influence & 0.852 & 3 \\
\hline (II)_Information Influence & 0.873 & 3 \\
\hline (SP)_Self-presentation & 0.873 & 4 \\
\hline CR)_Consumer resonance & 0.823 & 3 \\
\hline
\end{tabular}

Source: Survey Data

According to the Table 1, reliability coefficient ranged from .800 to .893 , although each above should indicate minimum cut off .70 The measurement indicators giving good condition on reliability it can be consider as accepted measurement range.

As it explained by Neuman, (2014) validity refers to an instrument in reality measures what is it expected to measure. Validity is measured through the using following tests. In order to satisfy convergent validity, following conditions should be satisfied. KMO value should be greater than 0.5 and sig. value of the Bartlett's Test of Sphericity should be less than 0.05 .

Table 2. Validity Test

\begin{tabular}{lcc}
\hline \multirow{2}{*}{ Test } & \multicolumn{2}{c}{ Validity } \\
\cline { 2 - 3 } & KMO & Sig. value of the Bartlett's Test \\
\hline Standard & $0.5<$ & $<0.050$ \\
Purchase Intention & 0.711 & 0.000 \\
Utilitarian Value & 0.767 & 0.000 \\
Hedonic Value & 0.794 & 0.000 \\
Tie Strength & 0.667 & 0.000 \\
Homophily & 0.743 & 0.000 \\
Trust & 0.708 & 0.000 \\
Normative Influence & 0.708 & 0.000 \\
Information Influence & 0.739 & 0.000 \\
Self-presentation & 0.800 & 0.00 \\
Consumer resonance & 0.721 & 0.00 \\
\hline
\end{tabular}

Source: Survey data 
According to the Table 2, all the dimensions have reached above 0.5 of KMO value. And also the Bartlett's Test of Sphericity less than 0.05 satisfied validity of the sample.

\section{Data Analysis and Results}

Researchers have collected the data by using online questionnaire form Google forms and distribute the questionnaires among the sample. Analyzed the data set with support of version 23.0. It is going to interpret the results by presenting an exploratory data analysis of the variables for the assumptions of statistical methods that used to achieve the objectives of the research.

\subsection{Descriptive Statistics for Demographic}

Descriptive statistics is the discipline of the main feature of the collection of information. In the sample data, there are two variables as dependent variable and independent variable. It has main three categories such as central tendency, measures of dispersion and graphs. Measure of central tendency includes the mean, median, and mode, while the measure of dispersion includes the standard deviation, standard error of mean, minimum and maximum value of variables. The demographic variables that receive attention are gender, age, level of education, profession, and monthly income.

The sample of this study represents 67.1 percent of males and 32.9 percent of females. As it reported in the Ministry of Transport \& Civil Aviation (2018) total number of driving license issued during the time period of 2015 to 2017 is 89,813 showing the ratio of 32.1 percent. Also Department of Census and Statistics, Computer Literacy Statistics -2017 , showed the digital literacy rate of male -42.5 percent and female -35.2 percent. Thereby it can conclude that sample which has selected mostly similar to the population figures. When it's come to the making purchasing decision regarding vehicle, Males are more involving than females. In this study higher proportionate of respondents responded by males.

\subsection{Descriptive Statistics for Variables}

The present study has been used 32 item scale which has been developed by Chiu (2006); Chu \& Kim (2011); Jahn \& Kunz (2012); Shang (2017) and three item scale to measure purchase intention developed by Lu (2010).

There are 8 variables that have been used to measure user generated content, namely, utilitarian value, Hedonic value, tie strength, homophily, trust, normative influence and information influence. Following table indicate the mean values and standard deviation of these variables.

Table 3. Descriptive Statistics for Independent Variable

\begin{tabular}{lcc}
\hline & Mean Value & Std. Deviation \\
\hline Utilitarian Value & 5.2935 & .84074 \\
Hedonic Value & 5.2476 & 1.01953 \\
Tie Strength & 4.5974 & 1.18423 \\
Homophily & 3.8277 & 1.40842 \\
Trust & 3.7520 & 1.41220 \\
Normative Influence & 4.7311 & 1.22502 \\
Information Influence & 5.1932 & 1.10808 \\
Self-Presentation & 5.2391 & 1.07693 \\
\hline
\end{tabular}

Note: Seven Point Likert Scale 1= Strongly Disagree, 2= Somewhat Disagree, 3= Disagree, 4= Neutral, 5= Agree, 6=Somewhat Disagree, 7=Agree

Source: Survey Data

As it showed in Table 3, highest mean value given in utilitarian value and lowest mean value generated in trust in 3.7520. Also following table illustrated the descriptive statistics for mediating variable consumer resonance and dependent variable purchase intention.

Table 4. Descriptive Statistics for Consumer resonance and Purchase intention

\begin{tabular}{lcc}
\hline & Mean & Std. Deviation \\
\hline Resonance & 5.2190 & 1.00663 \\
Purchase Intention & 5.1240 & .98925 \\
\hline
\end{tabular}

Note: Seven Point Likert Scale 1= Strongly Disagree, 2= Somewhat Disagree, 3= Disagree, 4= Neutral, 5= Agree, 6=Somewhat Disagree, $7=$ Agree

Source: Survey Data 


\subsection{Identify the Influence of Each Independent Variable on Purchase Intention}

\subsubsection{Regression Analysis}

Regression analysis is the analysis tool of the linear relationship between one variable and another variable(s). And also, this has been referred to as least squares regression and ordinary least squares (OLS).

Table 5. ANOVA Table

\begin{tabular}{llccccc}
\hline & Model & Sum of Squares & Df & Mean Square & F & Sig. \\
\hline 1 & Regression & 112.483 & 9 & 12.498 & 27.630 & $.000^{\mathrm{b}}$ \\
& Residual & 89.112 & 197 & .452 & & \\
& Total & 201.595 & 206 & & &
\end{tabular}

a. Dependent Variable: purchase Intention

b. Predictors: (Constant), Resonance, Homophily, Information, Utilitarian, Tie, Hedonic, Normative, Self-Presentation, Trust

Source: Survey Data

As per the ANOVA table, the significant value should be less than 0.05. According to the ANOVA table of this study, significant value is 0.000 . Therefore, a researcher has identified that the regression model of the study is statistically significant.

\subsubsection{R-squared}

$\mathrm{R}$ square is an indicator which analyzes the percentage of variation independent variable that can be explained by the independent variables. It attends as an easy and fast measure of explanation for the goodness of fit of the research mode.

Table 6. Model Summary

\begin{tabular}{cccccc}
\hline \multicolumn{5}{c}{ Model Summary } \\
\hline Model & $\mathrm{R}$ & R Square & Adjusted R Square & Std. Error of the Estimate & Durbin-Watson \\
1 & $.747^{\mathrm{a}}$ & .558 & .538 & .67257 & 1.610
\end{tabular}

a. Predictors: (Constant), Resonance, Homophily, Information, Utilitarian, Tie, Hedonic, Normative, Self-Presentation, Trust b. Dependent Variable: Purchase Intention

Source: Survey Data

According to the Model summary table 5.19, these independent variables are representing 55.8 percent of the dependent variable. In other words, the explanatory power of the independent variable is 55.8 percent.

Regression coefficient describes how well the values fit the data. While the influence is positive, the sign of the related coefficient is also positive. Coefficients for negative influence have negative signs. It is described as the movement in the dependent variable for a one-unit change in the independent variable - holding all other independent variables constant.

Table 7. The Result of positive Relationships

\begin{tabular}{ccccccc}
\hline & Relationship & Beta Value $(\beta)$ & SE & T & P- Value & Decision \\
\hline H1a & UV- CR- PI & 0.6143 & 0.0718 & 8.558 & 0.000 & Supported \\
H1b & HV - CR- PI & 0.5987 & 0.0548 & 10.9178 & 0.000 & Supported \\
H2a & TS- CR- PI & 0.2947 & 0.5570 & 5.2923 & 0.000 & Supported \\
H2b & HO- CR- PI & 0.0411 & 0.4980 & 0.8255 & 0.410 & Not Supported \\
\hline H2c & TR- CR- PI & 0.0560 & 0.4960 & 1.1290 & 0.2602 & Not Supported \\
H2d & NI- CR- PI & 0.3848 & 0.5070 & 7.5892 & 0.000 & Supported \\
H2e & II- CR- PI & 0.4090 & 0.5670 & 7.2202 & 0.000 & Supported \\
H3 & SP- CR- PI & 0.4475 & 0.5730 & 7.8072 & 0.000 & Supported \\
\hline
\end{tabular}

Note: Significant level; $* \mathrm{P}<0.1 ; * * \mathrm{P}<0.05$

Source: Survey Data

As per the above Table 7, researchers have identified a Beta $(\beta)$ and their significance are important statistics. Beta of utilitarian value has given a value of 61 percent with significant value of 0.000 which shows a positive and significant relationship between utilitarian value and the consumer resonance. Beta of hedonic value has given the value of 60 percent, whereas, significant value of 0.000 which again shows a positive and significant 
relationship between the hedonic value and the consumer resonance. Beta of tie strength has generated the value of 29 percent with a significant value of 0.000 which shows a positive relationship between tie strength and consumer resonance. Beta of normative influence has given 38 percent where it's significant value of 0.000 which shows a positive and significant relationship with consumer resonance. Information influence also generates beta value of 41 percent with a significant value of 0.000 which again shows a positive and significant relationship between the information influence and the consumer resonance. Beta of self-presentation has given a value of 45 percent, whereas, significant value of 0.000 which shows a positive relationship between self-presentation and the consumer resonance. Beta of homophily value has given 4 percent with significant value of 0.4100 which shows that the prediction is supported the 4 percent confidence interval yet been impacted 4 percent among the other predictors it does not have comparative prominence in the model. But it has a positive relationship with the dependent variable. But it not significant according to the requirement. its significant level is .410 , but it should be lower .05 . Trust generates beta value of 5 percent whereas, significant value of 0.2602 which shows that the prediction is supported the 26 percent confidence interval yet been impacted 5 percent among the other predictors it does not have comparative prominence in the model. But it has a weak positive relationship with the independent variable and again not significantly influence on the consumer resonance.

\subsection{Measures the Variables}

Researcher developed the following model for using the aggregate mean value of the all variables.

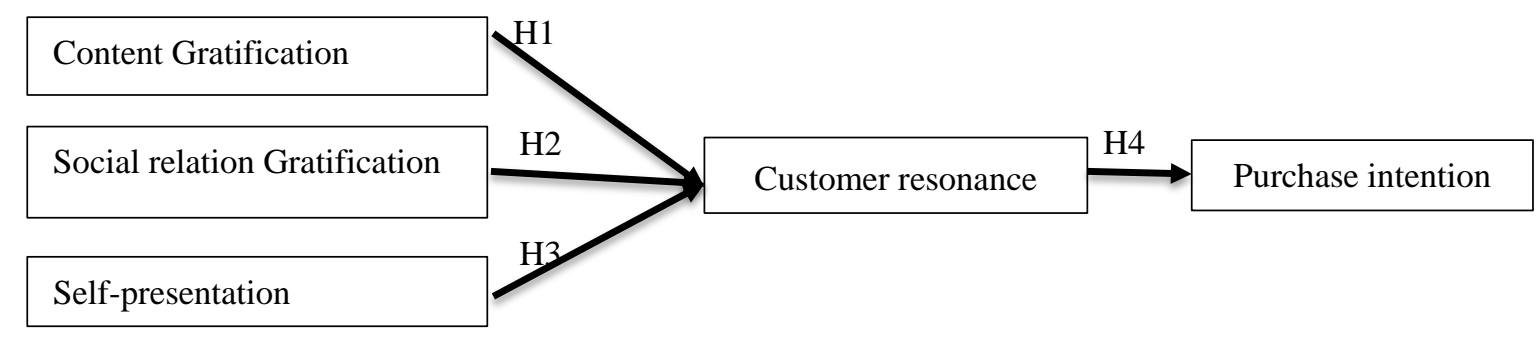

Source: Author

Table 8. Summary of Correlation Analysis

\begin{tabular}{ccccc}
\hline & P-Value & Decision & Beta Value $(\beta)$ & Relationship \\
\cline { 2 - 4 } CG-CR-PI & 0.000 & Accepted & 0.3799 & Positive \\
SR-CR-PI & 0.000 & Accepted & 0.5430 & Positive \\
SP-CR-PI & 0.000 & Accepted & 0.4475 & Positive \\
CR - PI & 0.000 & Accepted & 0.3970 & Positive \\
\hline
\end{tabular}

Source: Survey Data

According to this summary table all the hypotheses of the study is in within the range of significant and positive relationship (Shang, 2017). But the homophily and trust has not strong relationship towards the dependent variables. All their independent variables significantly impact on the purchase intention. Consumer resonance has significant relationship with the purchase intention of (P-Value) 0.000 .

\section{Discussion}

The main purpose of this study is identify the influence of user generated content on purchase intention of automobiles in Sri Lanka. These identifications based on the theoretical and supportive empirical findings and intention of addressing to the identified gaps while empirical evidences were carried to support the arguments. This study developed hypothesis derived from the theory of uses and gratifications to examine the how user generated content making an effect on the relationship between consumer resonance and purchase intention of automobiles.

The current study is having three main objectives namely; to identify the degree of which user generated content characteristics can influence consumers' purchase intention on the online environment, to examine the relationship between user generated content and purchase intention within the automobiles in Sri Lanka, to measure the influence of user generated on consumer resonance towards the automobiles in Sri Lanka. In terms of measuring the relationship and affects par with the developed hypotheses, researcher employed Statistical Package for the Social Science (SPSS).

The identification of user generated content researcher used the uses and gratification theory (Katz, 1973 as cited 
by Kunz, 2012) which eight main constructs derived namely utilitarian value, hedonic value, tie strength, homophily, trust, normative influence and information influence. In the current study it has found that the positive relationships and significant levels of $\mathrm{UV}(\beta=.0 .6143, \mathrm{t}=8.558, \mathrm{p}=0.000), \mathrm{HV}(\beta=0.5987, \mathrm{t}=10.9178$, $\mathrm{p}=0.000) \mathrm{TS}(\beta=0.2947, \mathrm{t}=5.2923, \mathrm{p}=0.000), \mathrm{HO}(\beta=0.0411, \mathrm{t}=0.8255, \mathrm{p}=0.410), \mathrm{TR}(\beta=0.0560, \mathrm{t}=1.1290$, $\mathrm{p}=0.2602)$, NI $(\beta=0.3848, \mathrm{t}=7.5892, \mathrm{p}=0.000)$, II $(\beta=0.4090, \mathrm{t}=7.2202, \mathrm{p}=0.000)$ and $\mathrm{SP}(\beta=0.4475, \mathrm{t}=$ $7.8072, \mathrm{p}=0.000$ ) on purchase intention. Therefore, homophily and the trust variables not significantly influence on purchase intention. It can be concluded that hypothesis of homophily and trust variables not supported and other variables making positive and significant influence on consumer resonance.

Uses and gratification theory divided in to three variables namely, content gratification, social relation gratification and self-presentation gratification. These three variables have sub variables. The content gratification has sub variables namely, utilitarian value (UV), hedonic value (HV). The social relation gratification has five sub variables namely, tie strength (TS), homophily (HO), trust (TS), normative influence (NI) and information influence (II). Therefore, the researcher employed the aggregate mean value of each sub variables on positive relationship of $\mathrm{CG}(\beta=.0 .3799, \mathrm{p}=0.000), \mathrm{SR}(\beta=.0 .543, \mathrm{p}=0.000)$ and $\mathrm{SP}(\beta=.0 .4475, \mathrm{p}=$ $0.000)$. Hence, it can be concluded that each hypothesis supported by making positive and significant influence on consumer resonance.

In order to that mediate factor which is consumer resonance, positively relationship of $(\beta=.0 .397, p=0.000)$ on Purchase intention. Hence, it can be concluded that hypothesis supported by making positive and significant influence on purchase intention of automobiles.

Significant findings of the study through the context of automobiles in Sri Lanka, Homophily which is similar characteristics of individuals on Facebook, not significantly influence on resonance behaviour on Facebook pages. And also the trust is also not significantly influence on resonance behaviour. Facebook followers on Sri Lanka not concern the similar characteristics of members in their groups and also they are not trust the members on their friend list. Hence, the influence of homophily and trust have weak relationship between the consumer resonance behaviour in current research context would not significant. As for the understanding of these insights, researcher predicts a performance gap in automobiles diffusion compared to other countries.

Consumer behaviour on automobiles, people will be looking for social status, utility value of the content, hedonic value of the content on online environment. As it points out by the Herath \& Wijesundara, (2008), in Sri Lankan consumers in online search for durability goods through search more information about the products. Based on above said argument it has proven to be in line with content by a positive behaviour of the consumer resonance. In order to that Shang, (2017) found out the weak relationship and not significant influence on homophily and trust factors on consumer resonance on social networks sites. Thereby, it can conclude that current research study demonstrating different forms of user generated content on the purchase intention towards automobiles.

\section{Theoretical Implication}

This study intended to explain when the consumer resonance mediate on relationship between user generated content and purchase intention in the context of automobiles in Sri Lanka. As the Uses and gratifications (U\&G) theory discussed, social need and psychological need are involved in creating expectations of the social media in which the different gratification needs that the people possess results in different means and modes of media usage. The emergence of social technologies and choices of mass communication, cater to different needs. In this context the researcher has identified that many consumer's influence by their needs once they get in to the decision making process of automobiles. As in general, automobiles are high involvement products and it mainly influence the consumer psychological needs while they show off and it impact on their social status. Therefore, making a purchase decision over technological products like automobiles, it is very complex and influence several factors. Giving and understanding this complex situation in online environment, this study contributes to the existing theory as it is explained how different gratification needs that fulfill the consumer's social and psychological needs that generated expectations towards the social media.

According to the Shang, there are many of the characteristics which are affecting the user generated content and consumer resonance towards purchase intension. The researcher has identified those characteristics according to the Shang studies. As per the above implication, purchase intention over a technological and high involvement product like automobiles brings very complex situation for every customer. Yet there are limited insights provided by the existing theories to guide for a proper consumption decision and creating a need. 


\section{Managerial Implications}

The significance of this study is not limited to the automobile industry. It also generalized framework of what happen to the online consumer intention to purchase of global automotive market and respective technologies which it near the target audience.

This study finding will enable automotive marketers to make proper marketing strategies for their social media campaign while crafting strategies to make consumer resonance behaviour towards the intention to purchase. Consumer resonance behaviour may lead to an effective purchasing decision and it enables to reach the consumers. Therefore, companies should put their effort into developing appealing and informative product content on social media where it gives the proper direction to users manage their self-presentation and image management behavior. This could result in consumer resonance on Facebook.

The purchase decision of automobiles will make an influence on other several industries like banking, insurance, government institutes. Therefore, having proper understanding about the consumer segments and industry trends will positively influence the consumer behaviour.

\section{Limitation of the Study}

This research context considered in the generalized to the all island sample was selected only from the Western Province, Sri Lanka and the sample size 207 which is small to generalize the results into entire country. Because of it is impossible to collect data from all regions in Sri Lanka due to the time limitation. Secondly, it is difficult to find former researches, journal articles related to user generated content relates to purchasing intention. Thereby it leads to limited access to get the proper background knowledge about the study. Thirdly, this paper consists the eight independent variables and mediate variable which will impact on purchasing decision on automobiles in Sri Lanka. But there can be other variables which also affect the purchasing intention. The researcher could not consider these variables in this study. Finally, there is a chance that given responses are not truly monitored and view on each statement in the questionnaire which may generate fraudulent answers. And also these answers which are involved with respondents such as language problem, different mental conditions etc.

\section{Suggestion for Future Researches}

This research has achieved the set of objectives and opened avenues and directions for future research. The findings highlight the need for future studies that should explore more variables affecting purchasing decisions on the automobiles within the social media environment. The risk level is a prominent factor that takes decision in an online environment which is major factor influence heavily on purchasing intention which are not covered under this study.

The current study focused on Sri Lanka automobiles only, the results may be applicable to other market segment as well. For an example, it is reasonable to suggest that user generated content may have a greater influence on products that are more likely to be purchased online (such as the fashion industry, hotel reservations, tour packages) than on those sold mainly offline.

\section{Conclusions}

This study was based on the user generated content and purchase intention of automobiles in Sri Lanka. Research have gone through user generated content to measure the respondents' independent variables and purchase intention. The study performed to identify user engagement level of auto page's followers on Facebook, to analyze the level of user generated content characteristics, to identify the relationship of each user engagement characteristic of purchase intention of automobiles in Sri Lanka and to determine the most significant user engagement characteristic with the content on purchase intention of automobiles.

The researcher has selected the sample 207 respondents within the western province who are following auto pages on Facebook. Offered a questionnaire which is already validated by Shang, (2017) to the select sample. After the researcher have educated the collected data in accordance with user engagement on Facebook. After researcher have evaluated the collected data in accordance with user generated content. Exploratory Data Analysis (EDA), demographic analysis, descriptive analysis, correlation, regression analysis was done through SPSS statistical data analysis software. Based on the analysis results, the objectives were achieved, and the hypothesis was tested.

The objective of this whole research were based on: (1) To identify the degree of which user generated content characteristics can influence consumers' purchase intention on the online environment, (2) To examine the relationship between user generated content and purchase intention within the automobiles in Sri Lanka, (3) To 
measure the influence of user generated on consumer resonance towards the automobiles in Sri Lanka. And finally gave the recommendation and further research direction in this paper.

By the conducting a comprehensive literature review on the research topic, the researcher was able to identify mainly user generated content indicators. Further, the researcher was able to identify mediating these factors through consumer resonance. Hypothesis were developed and tested by the researcher and it was found that the homophily and trust do not make significant impact on the consumer resonance, creating the purchase intention.

In order to make sure that there is no problem associating to the questionnaire and with the objective of building a quality questionnaire, used previous studies for get the proper understanding. Calculate Cronbach alpha values have proved the reliability of the questionnaire and which then only the researcher can identify whether collected data normal or not.

According to the findings, there is significant and positive relationship between the independent variable and the dependent variable. It can be concluded that the researcher accepted the alternate hypothesis. Because all hypothesis gets the positive coefficient values that indicate positively affect and homophily and trust variables not significantly affect the purchase intention. It can be concluded that researcher accepted alternative hypothesis $\mathrm{H} 2 \mathrm{~b}$ and $\mathrm{H} 2 \mathrm{c}$ because of the positive relationship. (H0- there is no positive relationship between User generated content and purchasing intention towards automobiles in Sri Lanka). Also correlation value of 4 percent indicates that there is the weak positive relationship between homophily and the consumer resonance and the correlation value 5 percent indicates that there is the weak positive relationship between homophily and the consumer resonance. According to the significant level of the homophily and trust which are not represent the acceptable level. Acceptable level of significant level should be $>=0.05$. But the findings of the study represent the homophily is 0.410 and trust variable represent the 0.2602 of significant values. Therefore, researcher found out the similar characteristics of users (homophily) and trust of the members on Facebook not supported for the developed hypothesis.

Finally, the researcher is giving some suggestions to future researchers who are interested in the social media environment. It is evident that the results are significant to give valuable recommendations and insights about the subject matter and needed suggestions for future will be explained under the above future research areas in detail manner.

\section{References}

Akbayrak, B. (2000). A Comparison of Two Data Collecting Methods: Interviews and Questionnaires. Journal of Education, 18(1), 1-10. Retrieved from http://www.efdergi.hacettepe.edu.tr/200018BURCUAKBAYRAK. pdf

Anderson, J. C., \& Gerbing, D. W. (1998). Structural equation modeling in practice: A review and recommended two-step approach. psychological bulletin, 103(3), 411-423.

Azi, L. (2015). Uses and gratifications of members of communities of practice. Online InformationReview, 39(2), 163-178. https://doi.org/10.1108/OIR07-2014-0170

Barker, V. (2009). Older adolescents' motivations for social network site use: The influence of gender, group identity, and collective self-esteem. CyberPsychology \& Behavior, 12, 209-13.

Batra, R., \& Ahtola, O. T. (1990). Measuring the hedonic and utilitarian sources of consumer attitudes. Marketing letters, 2(2), 159-170.

Berthon, P. P. (2008). When customers create the ad. California management review, 50(4), 6-30.

Blumberg, B. C., \& Schindler, P. S. (2008). Business Research Methods (2nd ed.). McGraw-Hill Higher Education.

Burmann, C. (2010). A call for User-Generated Branding. Journal of Brand Management, 18, 1-4. https://doi.org/10.1057/bm.2010.30

Chari, S., Christodoulides, G., Resi, C. W., \& Casaletto, J. (2016). Consumer trust in usergenerated brand recommendations on Facebook. Physhology and marketing, 33(12), 1071-1081.

Chen, Y. H., \& Lin, C. C. (2010). Website attributes that increase consumer purchase intention: A conjoint analysis. Journal of business research, 63(9-10), 1007-1014.

Chevalier, J. A., \& Mayzlin, D. (2006). The effect of word of mouth on sales: Online book reviews. Journal of marketing research, 43(3), 345-354.

Chigona, W. K. (2008). The uses and gratifications of mobile internet among the South African students. 
Portland International Conference (pp. 2197-2207).

Chu, S. C., \& Kim, Y. (2011). Determinants of consumer engagement in electronic wordof-mouth (eWOM) in social networking sites. International journal of Advertising, 30(1), 47-75.

Dholakia, U. M. (2001). A Motivational Process Model of Product Involvement and Consumer Risk Perception. European Journal of Marketing, 35(12), 1340-1362.

Ghose, A., \& Ipeirotis, P. G. (2011). Estimating the helpfulness and economic impact of product reviews: Mining text and reviewer characteristics. IEEE Transactions on Knowledge and Data Engineering, 23(10), $1498-1512$.

Goffman, E. (1959). The presentation of self in everyday life. Golden City, NY: Doubleday.

Gogoi, B. J. (2013). Study of Antecedents of Purchase Intention and its Effect on Brand Loyalty of Private Label Brand of Apparel. International Journal of Sales and Marketing Management Research and Development, 3(2), 73-86.

Griskevicius, V. T., \& Van den Bergh, B. (2010). Going Green to be Seen: Status, Reputation, and Conspicuous Conservation. Journal of Personality and Social Psychology, 98(3), 392-404. https://doi.org/10.1037/a0017346

Hazari, S. B., \& Sethna, B. N. (2016). Hedonic and utilitarian use of user-generated content on online shopping websites. Journal of Marketing Communications, 22. Retrieved from https://www.researchgate.net/publication/320785873v

Herath, H. M., \& Wijesundara, C. B. (2008). Factors affecting online purchase decisions of Sri Lankan consumer: With special reference to Western province. International Conference on Social Sciences, Sri Lanka (p. 47). University of Kelaniya.

Hoffman, D. L., \& Fodor, M. (2010). Can you measure the ROI of your social media marketing? MIT Sloan Management Review, 52(1), 41.

Jahn, B., \& Kunz, W. (2012). How to transform consumers into fans to your brand. Journal of service management, 344.

Kaplan, A. M., \& Haenlein, M. (2010). Users of the World Unite! The Challenges and Opportunities of Social Media. Business Horizons, 53(1), 59-68.

Karunanayake, R. T., \& Wanninayake, W. B. (2015). Impact of Key Purchasing Determinants on Purchase Intention of Hybrid Vehicle Brands in Sri Lanka, an Empirical Study. Journal of Marketing Management, 40-52. https://doi.org/10.15640/jmm.v3n1a4

Katz, E. H., \& Gurevitch, M. (1973). On the use of the mass media for important things. American Sociological Review, 164-181.

Kim, D. J., \& Rao, H. R. (2008). A trust-based consumer decision-making model in electronic commerce: The role of trust, persived risk, and their antecedents. Decision Support Systems, 44(2), 554-594. Retrieved from http://ink.library

Kim., J. (2012). The institutionalization of YouTube: From user-generated content to professionally generated content. Media, Culture \& Society, 34(1), 53-67. https://doi.org/10.1177/0163443711427199

Kopp, S. (2010). Social resonance and embodied coordination in face-to-face conversation with artificial interlocutors. Speech Communication, 52(6), 587-597.

Lee, J. P., \& Han, I. (2008). The effect of negative online consumer reviews on product attitude: An information processing view. Electronic commerce research and applications, 7(3), 341-352.

Li, Y. M., \& Shiu, Y. L. (2012). Adiffusion mechanism for social advertising over micro blogs. Decision support system, 54(1), 9-22.

Libai, B. B., \& Risselada, H. E. (2010). Customer to customer interaction: Boardening the scope of word of mouth research. Journal of service research, 267-282.

Malhotra, N. H., J., S. M., \& Oppenheim, P. (2007). Essentials of Marketing Research. An Applied Orientation. Retrieved from https://books.google.com/books?id=cDLiBAAAQBAJ\&pgis=1

Mangold, W. G., \& Fauld, D. J. (2009). Social media: The new hybired element of the promotiomn mix. Business Horizons, 52(4), 357-365. 
Mark, V. R., \& Natasha, L. (2003). Further Validation of the Motivation Toward the Environment Scale. Environment and Behavior, 35(4), 486-505.

Mũniz, A. M., \& Schau, H. J. (2007). Vigilante marketing and consumer-created communications. Journal of Advertising, 36(3), 35-50.

Neuman, W. L. (2014). Social Research Methods: Qualitative and Quantitative Approaches. Relevance of social research, 8. https://doi.org/10.2307/3211488

Riegner, C. (2007). Word of mouth on the web: The impact of Web 2.0 on consumer purchase decisions. Journal of advertising research, 47(4), 436-447.

Roy, S. K. (2009). Internet uses and gratifications: A survey in the Indian context. Computers in Human Behavior, 25(4), 878-886.

Selejan, A. (2014). Consumer's Behaviour in Relation to the Purchase of an Electric Vehicle. Aarhus University Department of Business Administration and Social Sciences, 51.

Shang, S. S., Wu, Y., \& Sie, Y. (2017). Generating consumer resonance for purchase intention on social media. Computers in Human Behaviour, 18-28.

Shao, G. (2009). Understanding the appeal of user-generated media: A uses and gratification perspective. Internet Research, 7-25.

Shin, D. H. (2009). Virtual gratifications of wireless Internet: Is wireless portable Internet reinforced by unrealized gratifications? Telematics and Informatics, 26(1), 44-56.

Solis, B. (2010). Social Media’s Critical Path: Relevance to Resonance to Significance. HBR Blog Network.

Stafford, T. F., \& Schkade, L. L. (2004). Determining uses and gratifications for the Internet. Decision sciences, 35(2), 259-288.

Sweeney, J. C., \& Soutar, G. N. (2001). Consumer perceived value: The development of a multiple item scale. Journal of retailing, 77(2), 203-220.

Tickle-Degnen, L., \& Rosenthal, R. (1990). The nature of rapport and its nonverbal correlates. Psychological inquiry, 1(4), 285-293.

Voss, K. E., \& Grohmann, B. (2003). Measuring the Hedonic and Utilitarian Dimensions of Consumer Attitude. Journal of Marketing Research, 40(3), 310-320.

West, R. L., \& Turner., L. H. (2010). Uses and Gratifications Theory. Introducing Communication Theory: Analysis and Application. Boston: McGraw-Hill: print.

You, Y., Vadakkepatt, G., \& Joshi, A. (2015). A meta-analysis of electronic word-of-mouth elasticity. Journal of Marketing, 79(2), 19-39.

Zolait, A. H. (2014). The nature and components of percived behavioural control as an element of theory of planned behaviour. Behaviour \& information Technology, 65-84.

\section{Copyrights}

Copyright for this article is retained by the author(s), with first publication rights granted to the journal.

This is an open-access article distributed under the terms and conditions of the Creative Commons Attribution license (http://creativecommons.org/licenses/by/4.0/). 